\title{
DEVELOPMENT OF PRIOR PARTICLE BOUNDARY FREE HOT- ISOSTATIC-PRESSING PROCESS FOR INCONEL 718 POWDER
}

\author{
Litao Chang, Wenru Sun, Yuyou Cui, Rui Yang ${ }^{1}$ \\ Institute of Metal Research, Chinese Academy of Sciences \\ 72 Wenhua Road, Shenyang 10016, P.R. China
}

Keywords: Powder; Hot isostatic press; Prior particle boundary; Superalloy; Inconel 718

\begin{abstract}
Hot isostatic pressed (HIPed) powder metallurgy (PM) Inconel 718 has the potential to be applied in turbine engines. However, the precipitation of high-density carbide particles along the prior particle boundaries (PPBs) leads to its poor ductility and is the main obstacle to be overcome if further and wider applications are pursued. In the past few years, we conducted research aimed at solving this problem, and a HIPing method that could eliminate the PPBs was developed. This paper summarizes the results in three parts: the first is on the influence of HIPing temperature on microstructure and tensile fracture modes of the HIPed alloy; several temperatures ranging from below the Laves incipient temperature to super-solidus were selected. In the second part, typical heat treatments for Inconel 718 were employed for mechanical property optimization of the HIPed alloy. It is found that HIPing at super-solidus temperatures could completely eliminate the PPBs, but the grain size is large and detrimental Laves phase also present. In the third part, a new HIPing process was developed, which consists of a short time holding above the solidus and a long time annealing below the incipient temperature of the Laves phase. This process could produce alloy free of PPBs and Laves phase. After heat treatment, the mechanical properties of the alloy are excellent.
\end{abstract}

\section{Introduction}

The $\gamma^{\prime \prime}$ and $\gamma^{\prime}$ co-strengthened Ni-Fe based alloy Inconel 718 is widely used in aerospace, nuclear and petrochemical industries owing to its superior mechanical properties, excellent weldability and relatively low cost[1-3]. Among these applications, the cast and wrought (C\&W) version is frequently used in disks and shafts[4], while the cast version is always applied in turbine frames, cases and other structures with large size and complex geometry[2, 5]. As with other alloys processed using $\mathrm{C} \& \mathrm{~W}$ route, a large portion of material will be machined to obtain the final geometry, leading to considerable material loss and increase in processing cost. Owing to the slow cooling rate during solidification, cast components have coarse grain size, heavy dendritic segregation and relatively poor mechanical properties. Solidification defects, such as shrinkage cavities and porosity, also form in the castings [5]. Homogenization treatment and HIPing are always required to eliminate the segregation, to close the internal pores and to improve the quality of the castings.

Metal powder (near) net shape HIPing[6, 7], which can produce components with complex geometry, high material use ratio and improved microstructural uniformity, has been utilized for engine component manufacturing since the 1970 s[8, 9]. If this process can be employed for Inconel 718 component fabrication, the disadvantages in material use ratio and processing cost

\footnotetext{
${ }^{1}$ Contact e-mail: rvang@imr.ac.cn (Dr. Rui Yang)
} 
for $\mathrm{C} \& \mathrm{~W} 718$, and the disadvantages in microstructure uniformity and casting defects for cast 718 , can both be overcome. HIPed PM Inconel 718 has great potential to be applied to aero engines and other complex components demanding relatively high strength and microstructural uniformity.

Several investigations were conducted to develop HIPed PM Inconel 718 in the past decade[3, $10,11]$. The most troublesome problem that metallurgists encounter during process development is the preferential precipitation of high-density carbide particles at the PPBs[3, 12]. PPBs that are decorated with high-density carbide particles are detrimental to the HIPed PM alloys, not only to the ductility, but also to the low cycle fatigue properties. So the PPBs must be eliminated or at least the carbide particles at the PPBs must be reduced if further and wider applications are pursued. It is well known that HIPing temperature has the greatest influence on microstructure of the HIPed PM alloys compared to other parameters, such as pressure and holding time. Several researchers indicate that HIPing at higher temperature is beneficial to the elimination of the PPBs, but this leads to considerable grain growth[13,14]. Obviously coarse grained microstructure is not preferred in Inconel 718, which has a maximum thermal capacity of $650^{\circ} \mathrm{C}$. Then selection of the HIPing parameters for this alloy must aim to strike a balance between reduction of the amount of PPBs and maintaining a finer grain size.

The present work includes three parts. The first part covers the influence of HIPing temperature on microstructure and tensile fracture mode of the HIPed alloy, several temperatures ranging from below the incipient temperature of the Laves phase to super-solidus were selected. In the second part, the response of the alloy HIPed at an optimized temperature to typical heat treatments will be presented. Some of the results presented in these two parts have already been published $[15,16]$. The third part reports a new HIPing process that can eliminate the PPBs in HIPed PM Inconel 718 [17].

\section{Material and experiment}

A phosphorous and boron micro-alloyed Inconel 718 was selected for the present investigation. It has comparable strength and several times longer stress rupture life compared with Inconel 718 . The chemistry (wt.\%) of the alloy is $19.3 \mathrm{Cr}, 2.98 \mathrm{Mo}, 0.5 \mathrm{Al}, 1.04 \mathrm{Ti}, 4.94 \mathrm{Nb}, 0.031 \mathrm{C}, 0.008$ $\mathrm{B}, 0.023 \mathrm{P}, 53.5 \mathrm{Ni}$ and Fe balance (weight percent). The powder was prepared on an EIGA (electrode induction melting gas atomization) system, using a crucible-free melting method as described in[18]. The powder was sieved to pass the 140 mesh (size $<105 \mu \mathrm{m}$ ), poured into ANSI 304 stainless steel capsules, degassed, vacuum sealed and then HIPed.

All powder capsules were held at the HIPing temperature for $4 \mathrm{~h}$ under the pressure in the range of 150 to $160 \mathrm{MPa}$ and then cooled in the furnace to room temperature. The argon gas used for HIPing was kept in the furnace during the cooling process. The HIPing temperatures used are $1140^{\circ} \mathrm{C}, 1180^{\circ} \mathrm{C}, 1210^{\circ} \mathrm{C}, 1260^{\circ} \mathrm{C}$ and $1275^{\circ} \mathrm{C}$. The first two are respectively below and above the Laves phase incipient melting point (between $1150^{\circ} \mathrm{C}$ and $1160^{\circ} \mathrm{C}$ ) of the as-cast Inconel 718[19]; the third is below the temperature for carbide to begin to dissolve[20]; the fourth and the last are respectively at and above the solidus[20]. Pressurizing and heating during the HIP operation were conducted simultaneously in a QIH-15 mini-hipper.

Both solution plus aging and direct aging heat treatments were employed for the mechanical properties optimization of PM Inconel $718 \mathrm{HIPed}$ at $1210^{\circ} \mathrm{C}$. The detailed heat treatments are listed below: 
Solution plus aging: $980^{\circ} \mathrm{C} / 1 \mathrm{~h} / \mathrm{AC}+720^{\circ} \mathrm{C} / 8 \mathrm{~h} \stackrel{2 h}{\longrightarrow} 620^{\circ} \mathrm{C} / 8 \mathrm{~h} / \mathrm{AC}$

Direct aging: $720^{\circ} \mathrm{C} / 8 \mathrm{~h} \stackrel{2 h}{\longrightarrow} 620^{\circ} \mathrm{C} / 8 \mathrm{~h} / \mathrm{AC}$

In the third part, we have designed a new HIPing procedure as listed below:

$1265^{\circ} \mathrm{C} / 150 \mathrm{MPa} / 0.5 \mathrm{~h} \stackrel{F C}{\longrightarrow} 1140^{\circ} \mathrm{C} / 150 \mathrm{MPa} / 4 \mathrm{~h} \stackrel{F C}{\longrightarrow} \mathrm{RT}$

The alloy HIPed using this procedure was also heat treated using the schemes mentioned above, and tensile and stress rupture properties of the heat treated alloys were evaluated.

Optical microscopy (OM) and scanning electron microscopy (SEM) observations were carried out on the HIPed and HIPed plus heat treated samples that were manually ground, polished and chemically etched. The reagent is composed of $35 \mathrm{~g} \mathrm{FeCl}_{3}, 100 \mathrm{ml}$ hydrochloric acid, $40 \mathrm{ml}$ ethanol, $10 \mathrm{ml}$ hydrofluoric acid and 40ml deionized water. TEM observation was carried out on the twin-jet electro-polished (in a $10 \%$ perchloric acid methanol solution at -20 to $-30{ }^{\circ} \mathrm{C}$ and 16 V) foils on an FEI Tecnai F20 TEM. Energy dispersive spectroscopy (EDS) on the SEM and TEM was employed for the phase chemistry determination.

Grain size distribution of the HIPed alloy part was evaluated using electron backscattered diffraction (EBSD) data. The minimum grain size was set at $2 \mu \mathrm{m}$ and the minimum grain misorientation was set at $10^{\circ}$. Standard deviations $(\sigma)$ were calculated on the basis of the equivalent grain diameter to determine the grain size uniformity.

Tensile specimens having a gage diameter of $3 \mathrm{~mm}$ and gage length of $15 \mathrm{~mm}$ were machined from the HIPed alloys and then tested at $650^{\circ} \mathrm{C}$ in a Shimadzu AG-S 250KN tensile tester employing resistance heating, temperature fluctuation in the furnace being less than $3^{\circ} \mathrm{C}$. Tensile specimens for heat treated alloys have a gage diameter of $5 \mathrm{~mm}$ and length longer than $25 \mathrm{~mm}$. The tensile stress increase rate was kept constant at $200 \mathrm{MPa} / \mathrm{min}$ before the yielding point, and after yielding the chuck moving speed was kept constant at $3 \mathrm{~mm} / \mathrm{min}$ until fracture. Three specimens were tested for each HIPing condition. Fracture surfaces of the tensile fractured samples were observed on an SEM.

\section{Results and discussion}

\section{INFLUENCE OF HIPING TEMPERATURE}

\section{Microstructure of the as-HIPed alloys}

Fig. 1 presents the OM images of the alloys HIPed at different temperatures. No visible voids were observed for all alloys. PPBs were observed in all alloys $\mathrm{HIPed}$ at and below $1260^{\circ} \mathrm{C}$, and carbide particles are always precipitated at the PPBs. With increasing HIPing temperature, the amount of the PPBs and the amount of precipitates at the PPBs both decrease, see Fig. 1. PPBs were eliminated when the powders were HIPed at $1275^{\circ} \mathrm{C}$, in Fig. 1(e); However, a large amount of coarse Laves phase formed in the alloy, Fig. 1(f), and the grains are visibly much larger than the ones HIPed at or below $1260^{\circ} \mathrm{C}$. A large number of powder particles partially melted during HIPing, and a difference can be noted between the melted and the un-melded portion, as can be seen in Figl. (e, f). 

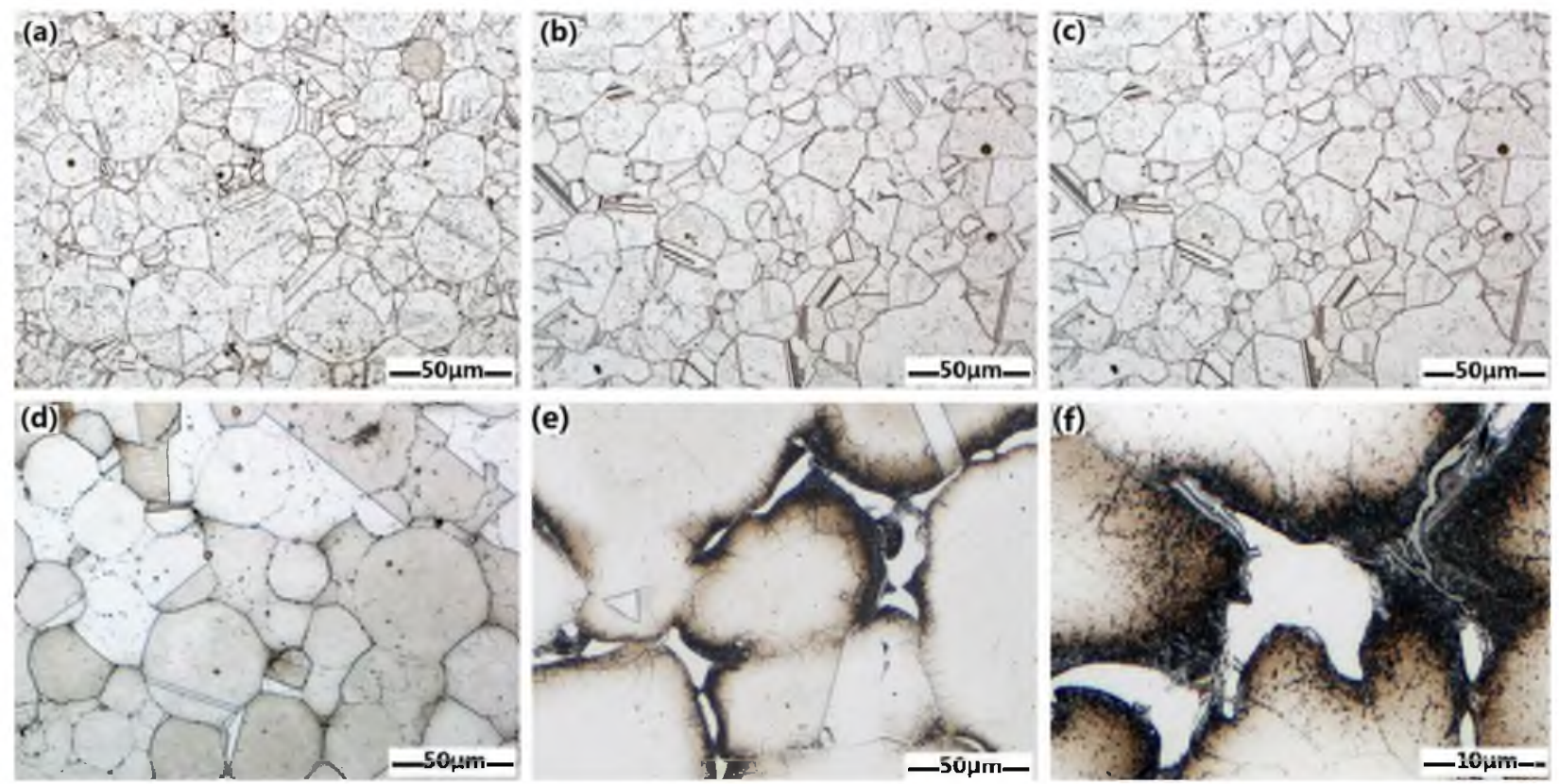

Fig. $1 \mathrm{OM}$ images of alloys HIPed at (a) $1140{ }^{\circ} \mathrm{C}$, (b) $1180^{\circ} \mathrm{C}$ (c) $1210^{\circ} \mathrm{C}$, (d) $1260^{\circ} \mathrm{C}$ and (e, f) $1275^{\circ} \mathrm{C}$, the scale of (f) being different from others.

$\gamma^{\prime}$ and $\gamma^{\prime \prime}$ phases precipitated during cooling process of HIPing, and their morphology and distribution are presented in Fig. 2. The precipitation is in cross array manner, with similar size and distribution for alloys HIPed at different temperatures; the diameter of the phases is less than $35 \mathrm{~nm}$. Weight fraction of the $\gamma^{\prime}$ and $\gamma^{\prime \prime}$ precipitates was determined to be about $14 \%$ for all HIPed alloys.
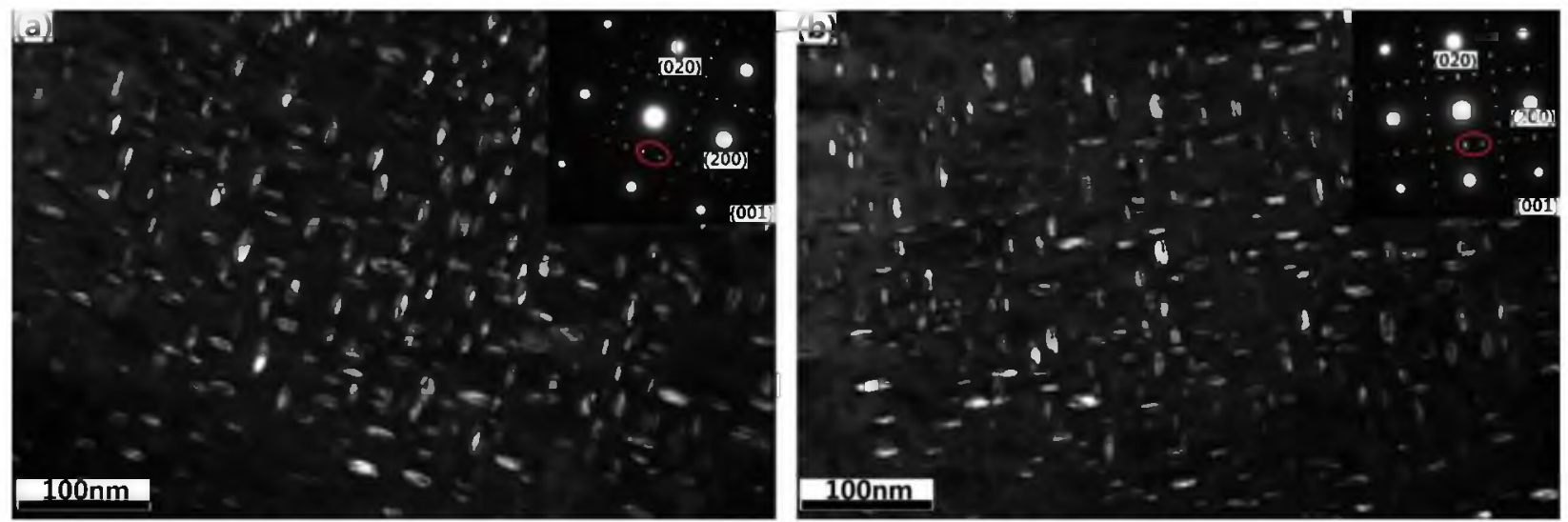

Fig.2 Dark field TEM images of $\gamma^{\prime \prime}$ and $\gamma^{\prime}$ phases in alloys HIPed at $1140^{\circ} \mathrm{C}(\mathrm{a})$ and $1260^{\circ} \mathrm{C} \mathrm{(b)}$. Reflections for imaging are indicated on the diffraction patterns shown as insets.

Table 1 Average grain size

\begin{tabular}{ccccc}
\hline HIPing temperature, ${ }^{\circ} \mathrm{C}$ & $1140^{\circ} \mathrm{C}$ & $1180^{\circ} \mathrm{C}$ & $1210^{\circ} \mathrm{C}$ & $1260^{\circ} \mathrm{C}$ \\
\hline Average grain size, $\mu \mathrm{m}$ & 21 & 27.4 & 28.2 & 50.3 \\
Standard deviation & 21.5 & 17.5 & 26.2 & 39.3 \\
Amount of grains larger & $1.1 \%$ & $0.4 \%$ & $2.8 \%$ & $10 \%$ \\
than 105 $\mu \mathrm{m}$ & & & & \\
\hline
\end{tabular}


Table 1 lists the average grain size of the alloys. Average grain size of the HIPed alloy increases with increasing HIPing temperature. Dramatic increase in grain size was observed when HIPing temperature was increased from $1210^{\circ} \mathrm{C}$ to $1260^{\circ} \mathrm{C}$, and about $10 \%$ of the grains have size exceeding the maximum size of the prior powder particles.
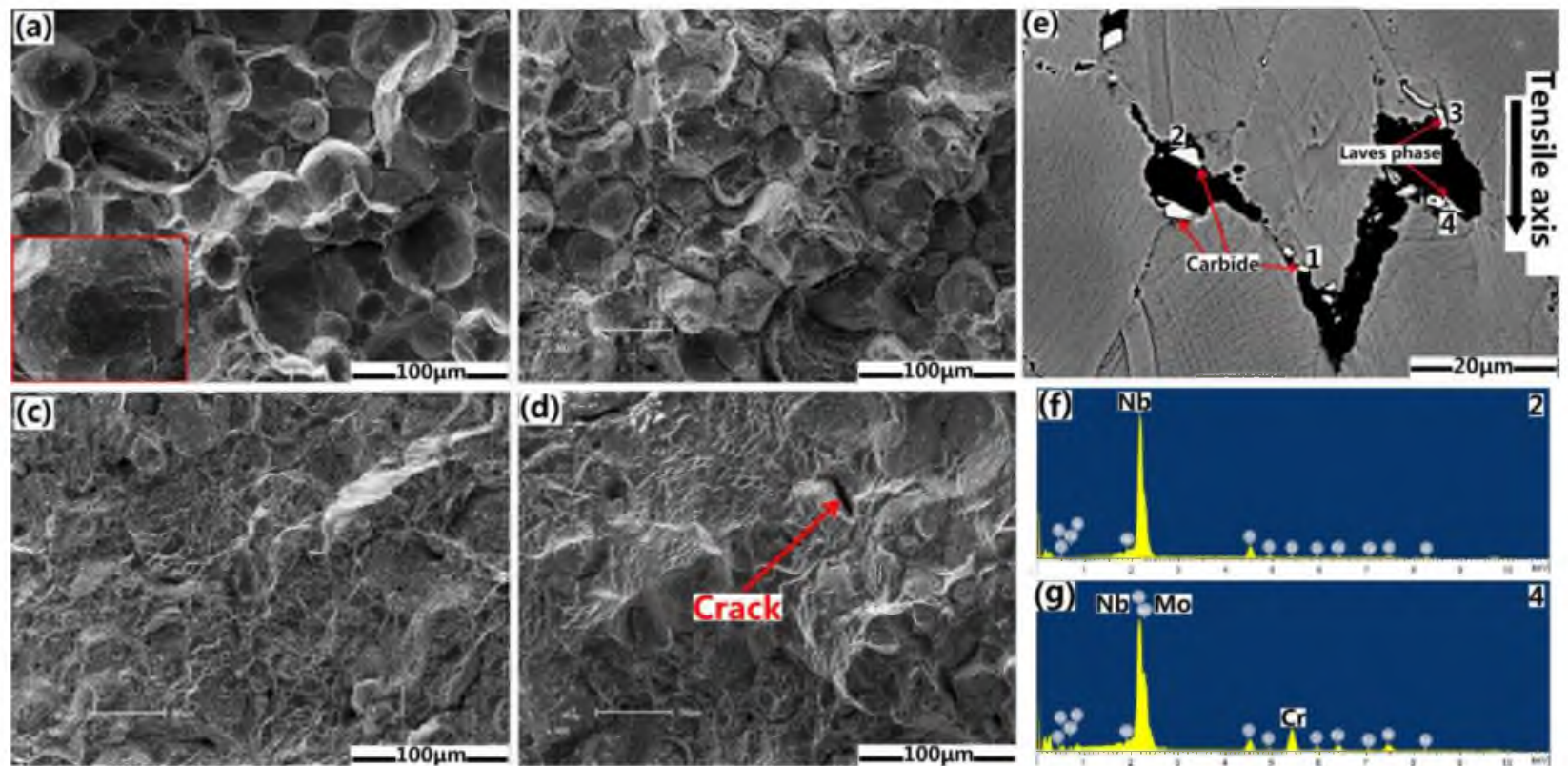

Fig.3 Fracture surfaces of the tensile samples from alloys HIPed at (a) $1140^{\circ} \mathrm{C}$, (b) $1180^{\circ} \mathrm{C}$, (c)

$1210^{\circ} \mathrm{C}$ and (d) $1260^{\circ} \mathrm{C}$. (e) is the longitudinal section microstructure of the tensile fractured sample from alloy HIPed at $1260{ }^{\circ} \mathrm{C}$ (a). (f, g) show the EDS spectra of the marked phases at the cracks in (e).

\section{Tensile Fracture Surface}

Fig.3(a-d) present the fracture surfaces of the samples tested at $650^{\circ} \mathrm{C}$. Fracture mode of the sample HIPed at $1140^{\circ} \mathrm{C}$ is inter-particle dominant fracture, Fig. 3(a)). The $1180^{\circ} \mathrm{C}$ HIPed sample features inter-particle fracture and has a mixed fracture mode with some ductile dimples. The inter-particle fracture area contributes to about $60 \%$ of the fracture surface, Fig. 3(b). The fracture surface shows an angle of about $45^{\circ}$ with the tensile axis for the sample HIPed at $1210^{\circ} \mathrm{C}$, having big dimples spread all over, Fig. 3(c). The fracture mode of the alloy HIPed at $1260^{\circ} \mathrm{C}$ also features dimple ductile fracture, similar to the sample HIPed at $1210^{\circ} \mathrm{C}$. One thing different is that cracks formed on the fracture surface, Fig. 3(d). Crack was also observed at the longitudinal cross section of the fractured specimens (Fig.3(e), HIPed at $1260^{\circ} \mathrm{C}$ ). EDS analysis indicated a concentration of Laves phase and coarse carbide particles at the cracks, see Fig. 3(f, g).

\section{RESPONSE TO HEAT TREATMENT}

From the results presented above, it could be judged that $1210^{\circ} \mathrm{C}$ is the most appropriate HIPing temperature for Inconel 718 powders, because grain size of the alloy HIPed at this temperature is moderate, and the inter-particle bonding is good because the tensile specimen HIPed at this temperature features a fully ductile dimple fracture mode. In the following, the alloy HIPed at 
$1210^{\circ} \mathrm{C}$ will be heat treated with the typical schemes for Inconel 718 , to optimize the mechanical properties and to understand the response of the HIPed alloy to heat treatment.

\section{Microstructure of the heat treated alloy}

Fig. 4 shows the microstructure of alloys subjected to direct aging $(a, c)$ or solution plus aging heat treatments $(b, d)$. Under SEM, the microstructure of the direct aged alloy is identical to that of the as-HIPed alloy. Carbide particles were precipitated at grain boundaries or PPBs. Small amounts of rod and needle shaped $\delta$ phase precipitated at the grain boundaries for the solution and aged alloy, Fig. 4(b). The grain size is similar to that of the direct aged alloy because of the pinning of $\delta$ phase. Fig.4(c, d) respectively present the morphology and distribution of the $\gamma^{\prime \prime}$ and $\gamma^{\prime}$ phases in the direct aged and solution and aged alloys. Heterogeneous distribution of the precipitates in the HIPed alloy was retained in the direct aged alloy. The difference is that the precipitates in the direct aged alloy are much coarser. For the solution and aged alloy, the precipitates are uniformly precipitated in the matrix in cross array manner. Statistical results indicate that the $\gamma^{\prime \prime}$ phase in the solution and aged alloy is in the size range between $15 \mathrm{~nm}$ and $35 \mathrm{~nm}$, with an average size of $23.7 \pm 6.4 \mathrm{~nm}$, while the $\gamma^{\prime \prime}$ phase in the direct aged alloy is in the size range of $10-50 \mathrm{~nm}$ and has an average diameter of $30 \pm 7.7 \mathrm{~nm}$.
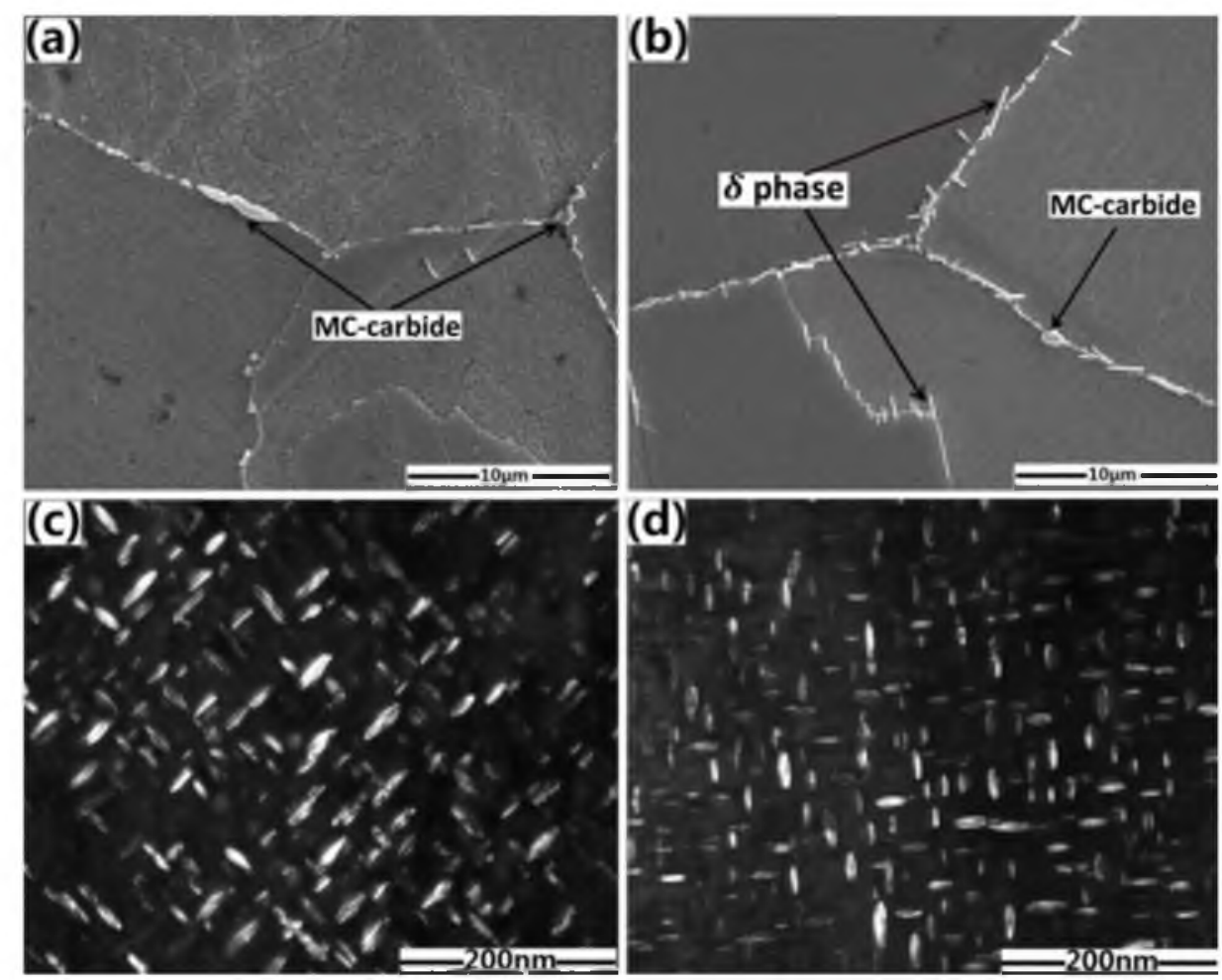

Fig. 4 Grain boundary precipitates and grain interior precipitates $\left(\gamma^{\prime \prime}\right.$ and $\left.\gamma^{\prime}\right)$ in alloys subjected to direct aging $(\mathrm{a}, \mathrm{c})$ or solution aging $(\mathrm{b}, \mathrm{d})$ heat treatment. The alloy was HIPed at $1210^{\circ} \mathrm{C} .(\mathrm{a}, \mathrm{b})$ are SEM images, $(\mathrm{c}, \mathrm{d})$ are TEM images.

\section{Mechanical properties of the heat treated allov}

Table 2 lists the tensile properties at $650^{\circ} \mathrm{C}$ for the as-HIPed alloy and the alloys subjected to heat treatment. The yield strength and ultimate tensile strength of the alloy after heat treatment were greatly improved, but the ductility decreased. The direct aged alloy shows much higher ductility (elongation $>16 \%$ ) than the solution and aged one, but the yield strength is a little lower. 
Over aging of the precipitates in the direct aged alloy is the main reason for its relatively low yield strength; detailed analysis can be found in [16]. Low ductility of the solution and aged alloy is due to the decrease in inter-particle bonding, which is a result of precipitation of $\delta$ phase and fine carbides during solution treatment. Evidence can be seen in Fig. 5: the direct aged alloy features a fully ductile fracture mode (Fig.5(a)), while the solution and aged alloy features an inter-particle fracture mode (Fig.5(b)).

Table 2 Tensile properties of the as-HIPed alloy and alloys subjected to direct aging or solution and aging heat treatments at $650^{\circ} \mathrm{C}$

\begin{tabular}{ccccc}
\hline & Y.S, MPa & UTS, MPa & Elongation, \% & R.A., \% \\
\hline As-HIPed & $790 \pm 5$ & $996 \pm 3$ & 20 & 24 \\
Direct Aged & $945 \pm 1$ & $1094 \pm 2$ & $16 \pm 1$ & $22 \pm 1$ \\
Solution and aged & $997 \pm 3$ & $1103 \pm 3$ & $4 \pm 1$ & $9 \pm 2$ \\
Specification for & $>860$ & $>1000$ & $>12$ & $>12$ \\
Inconel718 & 795 & 895 & 10 & 10 \\
Cast 718 at $600^{\circ} \mathrm{C}$ & & & 10 & \\
\hline
\end{tabular}

Note: 1) Y..S stands for $0.2 \%$ yield strength; UTS, ultimate tensile strength; R.A., reduction in area. 2) Tensile properties of cast 718 are from ref [21]
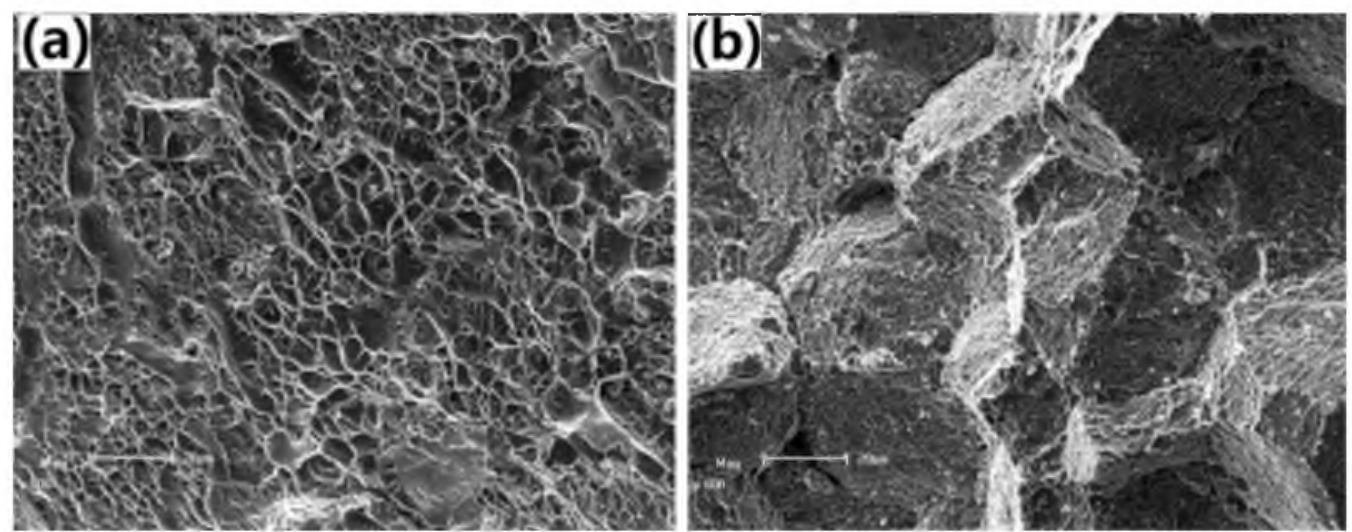

Figure 5 Fracture surface of the direct aged alloy (a) and solution and aged alloy (b).

\section{ELIMINATION OF PPBs}

\section{$\underline{\text { A new HIPing scheme }}$}

From the results presented above, it can be concluded that: (1) Direct aging is a better heat treatment for HIPed PM Inconel 718 than solution and aging because it ensures a good balance of strength and ductility. (2) The inter-particle bonding for alloy HIPed at $1210^{\circ} \mathrm{C}$ is not so good because it was weakened during solution treatment, because PPBs still exist. Evidently, these results are not satisfactory. A new HIPing process must be devised that can fully eliminate the PPBs.

During work on HIPing temperatures, we found that HIPing above the solidus can fully eliminate the PPBs. However, undesired brittle Laves phase exists and the grains are coarse. As is well known, Laves phase can be eliminated through annealing below its incipient temperature. According to Ashby's HIPing diagrams, superalloy powders can be fully compacted within tens of minutes when the HIPing temperature is higher than $1200^{\circ} \mathrm{C}$ [22]. We realised that the holding time of the HIPing process could be shortened to avoid excessive grain growth during HIPing. 
We thus proposed a new HIPing scheme that is capable of eliminating the PPBs while maintaining relatively fine grain size.

The new HIPing process consists of two steps: the first is performed above the solidus within a short time, with the aims of densifying the loose powders, eliminating PPBs by forming a certain amount of liquid and avoiding excessive grain growth. The second step is performed below the melting temperature of Laves phase, with the intention of eliminating the undesirable Laves phase formed during the cooling process after step one. The HIPing procedure, designed on the basis of the above principles, is listed in the experimental section.

The HIPing process was performed in an apparatus with a relatively fast cooling rate to reduce the amount of precipitates formed during the cooling process and to increase the yield strength of the direct aged alloy.
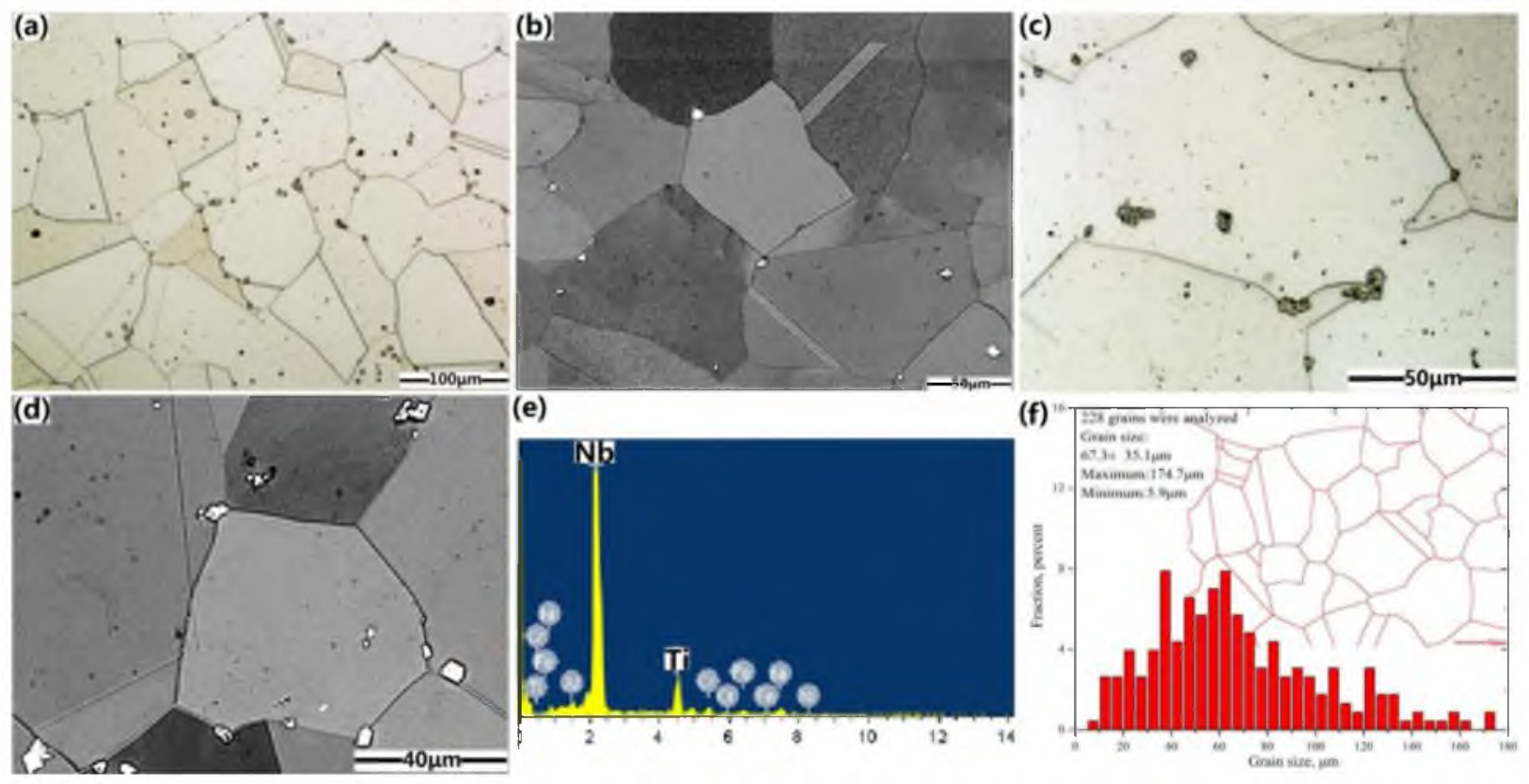

Fig.6 Microstructure of PM Inconel 718 HIPed using the new scheme: (a, c) OM images; (b, d) are back scattered electron SEM images. (c, d) show the carbide aggregates and (e) shows the EDS spectrum of the carbide particle in (d); (f) shows the grain size distribution histogram.

\section{Microstructure of the HIPed alloy}

Fig. 6 presents the microstructure of the alloy HIPed using the new procedure. An equiaxed grain microstructure was obtained. PPB decoration was not observed in the alloy, Fig. 6(a). The grain boundaries are decorated with a number of coarse carbide particles, Fig. 6(b). From higher magnification images, Fig. 6(c, d), it can be seen that some of the carbide particles aggregated together. The grain size distribution of the alloy was determined and is shown in Fig.6(f). Grain size is in the range between $5.9 \mu \mathrm{m}$ and $174.7 \mu \mathrm{m}$, with an average size of $65.7 \mu \mathrm{m}$. Over $16 \%$ of the grains exceed the maximum diameter $(105 \mu \mathrm{m})$ of the powders. These results show that the PPBs has been eliminated with this new HIPing scheme, although the grain size is a little large. The grain size can be reduced with further optimization of processing parameters. 
Coarse carbide particles at the grain boundaries are unexpected. Formation of these carbide particles can be interpreted as follows: at the end of the first step, the powder particles were fully compacted, and the alloy contained a certain amount of liquid. Carbide particles were partially dissolved and the un-dissolved ones would float in the liquid; during cooling after step 1, a small number of carbide particles would re-precipitate in the liquid and the liquid phase would form gamma phase and Laves phase. But owing to the low cooling rate, a few carbide particles would be nucleated, these new precipitated carbide particles and the un-dissolved ones would float on the liquid and be pushed to the residual liquid during the solidification. These carbide particles aggregated when the liquid solidified. During the second step of HIPing, Laves phase gradually dissolved, and $\mathrm{Nb}$ from the Laves phase would also facilitate the growth of the carbide particles.

\section{Mechanical properties of the heat treated alloy}

Table 3 lists the mechanical properties of the alloy subjected to heat treatment. Yield strength, ultimate tensile strength, elongation and reduction in area for the direct aged and solution and aged alloy are similar at both room temperature and $650^{\circ} \mathrm{C}$. From these results, it can be seen that the elongation and reduction in area are similar for both the direct aged alloy and solution and aged alloy. Yield strength of the direct aged alloy is also improved with the utilization of the HIPing apparatus with fast cooling rate. All the tensile properties of the alloy have met the specification of Inconel 718 and have exceeded the tensile properties of typical cast 718 . The stress rupture life of the alloy is comparable to phosphorous and boron micro-alloyed Inconel 718 processed using the cast and wrought route.

The fracture surfaces of the tensile samples were examined to see if evidence of residual PPBs could be identified. Results are presented in Fig. 7. The as-HIPed alloy, direct aged alloy and solution and aged alloy all feature fully dimpled ductile fracture when tested at $650^{\circ} \mathrm{C}$. These results confirm the previous conclusion that the new HIPing process eliminated PPBs for HIPed PM Inconel 718.

Table 3 Mechanical properties of the heat treated alloys

\begin{tabular}{|c|c|c|c|c|c|}
\hline \multicolumn{2}{|c|}{ Tensile property } & $\sigma_{0.2 .} \mathrm{MPa}$ & UTS, MPa & Elongation & R.A \\
\hline \multirow{4}{*}{$25^{\circ} \mathrm{C}$} & Direct aged & 1143 & 1300 & $21 \%$ & $35 \%$ \\
\hline & Solution and aged & 1142 & 1292 & $19 \%$ & $24.5 \%$ \\
\hline & $\begin{array}{l}\text { Specification for } \\
\text { Inconel } 718\end{array}$ & $1035-1167$ & $1275-1400$ & $12-21 \%$ & $15 \%$ \\
\hline & Cast 718 & 935 & 1100 & $16 \%$ & $26 \%$ \\
\hline \multirow{4}{*}{$650^{\circ} \mathrm{C}$} & Direct aged & 905 & 1032 & $21.6 \%$ & $34 \%$ \\
\hline & Solution and aged & 902 & 1023 & $20.8 \%$ & $24.7 \%$ \\
\hline & $\begin{array}{l}\text { Specification for } \\
\text { Inconel } 718\end{array}$ & $860-1000$ & $1000-1200$ & $12-19 \%$ & $15 \%$ \\
\hline & Cast 718 (at $600^{\circ} \mathrm{C}$ ) & 795 & 895 & $10 \%$ & $28 \%$ \\
\hline \multirow{4}{*}{$\begin{array}{l}\text { Stress } \\
\text { rupture }\end{array}$} & Temperature & stress & & Life & Elongation \\
\hline & \multirow{3}{*}{$650^{\circ} \mathrm{C}$} & \multirow{3}{*}{$690 \mathrm{MPa}$} & Direct aged & $457.1 \mathrm{~h}$ & $6.8 \%$ \\
\hline & & & $\begin{array}{l}\text { Specification } \\
\text { for Inconel } 718\end{array}$ & $>24 \mathrm{~h}$ & $>4 \%$ \\
\hline & & & P,B-Inconel 718 & $420 \mathrm{~h}$ & $45 \%$ \\
\hline
\end{tabular}

Note: Data of cast 718 are from [21]; P,B-In718 stands for phosphorus and boron micro-alloyed Inconel718; data of phosphorous and boron micro-alloyed Inconel 718 are from [23]. 

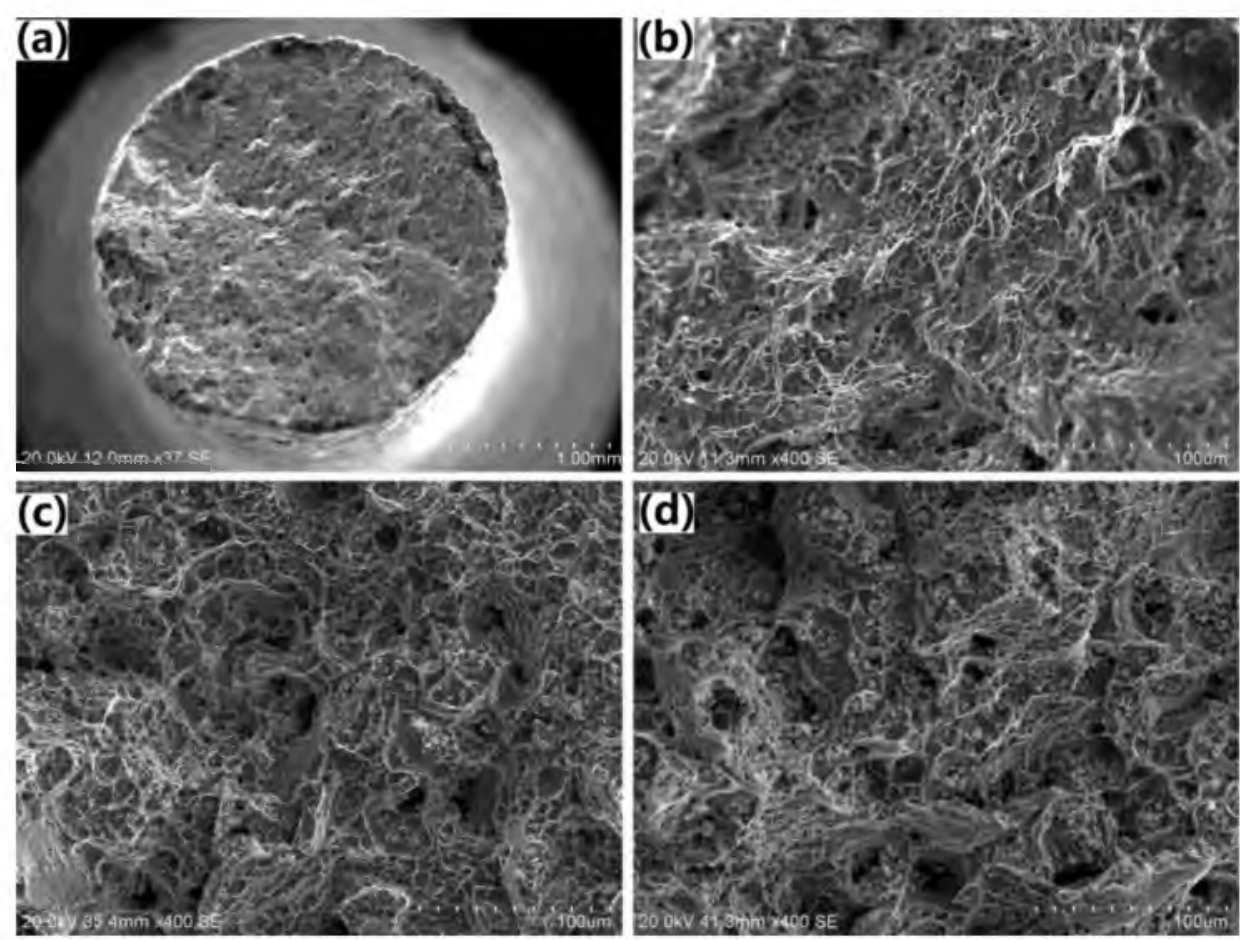

Fig. 7 Fracture surfaces of the as-HIPed alloy $(a, b)$, direct aged alloy $(c)$ and the solution and aged alloy $(d)$.

The method developed in the present study can also be applied to the compaction of other $\gamma^{\prime}$ phase strengthened nickel-based superalloys, which have much higher temperature capability than Inconel 718 and its derivatives. Care should be taken in selecting the temperature of the second step HIPing. It should be below the $\gamma / \gamma^{\prime}$ eutectic melting temperature, because $\gamma / \gamma^{\prime}$ eutectic is the final solidification product of this type of alloys.

\section{Conclusion}

An investigation to optimize the HIPing and heat treatment schemes for PM Inconel 718 was conducted. Several conclusions could be drawn as follows:

1. PPBs exist in all the alloys HIPed at and below $1260^{\circ} \mathrm{C}$. PPBs were eliminated when powders were HIPed at $1275^{\circ} \mathrm{C}$, but Laves phase formed and the grains are coarse. Tensile fracture mode of the HIPed alloy changed from inert-particle dominant fracture to fully dimpled ductile fracture with increasing HIPing temperature.

2. Direct aging treatment yields good ductility but relative low yield strength. Solution and aged alloy has poor ductility but high yield strength; the poor ductility is due to decrease in interparticle bonding during solution.

3. A new HIPing process was developed that can completely eliminate PPBs and produce alloy free of Laves phase. The alloy HIPed using the new scheme has good mechanical properties. 


\section{References}

1. A. Kracke, "Superalloys, the most successful alloy system of modern times-past, present and future" (Paper presented at The 7th Symposium on Superalloy 718 and Derivatives Pittsburgh, Pennsylvania, 2010), 13-50

2. G. Sjöberg, "Casting superalloys for structural applications" (Paper presented at The 7th Symposium on Superalloy 718 and Derivatives Pittsburgh, PA, 2010), 117-130

3. G.A. Rao, et al., "Effect of standard heat treatment on the microstructure and mechanical properties of hot isostatically pressed superalloy inconel 718", Mater. Sci. Eng. A, 355 (2003), 114-125

4. D.F. Paulonis, j.J. Schirra, "Alloy 718 at pratt\&whitney- histrorical perpective and future challenges" (Paper presented at Fifth International Symposium on Superalloys 718, 625, 706 and Various Derivatives, Pittsburgh, PA, 2001), 13-23

5. R.G. Carlson, J.F. Radavich, "Microstructural characterization of cast 718" (Paper presented at Superalloy 718-Metallurgy and Applications, 1989), 79-95

6. K. Zhang, et al., "Effect of hot isostatic pressing parameters on the microstructure and properties of powder Ti-6Al-4V hot-isostatically-pressed damples", Metall. Mater. Trans. A, 41 (2010),1033-1045

7. B. Ye, et al., "Enhanced densification of $\mathrm{Ti}-6 \mathrm{Al}-4 \mathrm{~V}$ powders by transformation-mismatch plasticity", Acta Mater, 58 (2010),3851-3859

8. G. Raisson, "Evolution of PM nickel base superalloy processes and products", Powder Metall, 51 (2008), 10-13

9. C. Bampton, et al., "Net-shape HIP powder metallurgy components for rocket engines" (Paper presented at International Conference on Hot Isostatic Pressing, 05, Paris, France, 2005), 1-10

10. G.A. Rao, et al., "Influence of modified processing on structure and properties of hot isostatically pressed superalloy Inconel 718", Mater. Sci. Eng. A, 418 (2006),282-291

11. U. Habel, "Microstructure and mechanical properties of HIP PM 718" (Paper presented at Fifth International Symposium on Superalloys 718, 625, 706 and Various Derivatives, 2001), 593-604

12. G.A. Rao, et al., "Characterisation of hot isostatically pressed nickel base superalloy Inconel* 718", Mater. Sci. Technol, 19 (2003),313-321

13. T. Prakash, et al., "Microstructures and mechanical properties of hot isostatically pressed powder metallurgy Alloy APK-1", Metall.Trans. A, 14 (1983),733-742

14. C.L. Qiu, et al., "Influence of hot isostatic pressing temperature on microstructure and tensile properties of a nickel-based superalloy powder", Mater. Sci. Eng. A, 564 (2013),176-185 
15. L. Chang, et al., "Influences of hot-isostatic-pressing temperature on microstructure, tensile properties and tensile fracture mode of Inconel 718 powder compact", Mater. Sci. Eng. A, 599 (2014), 186-195

16. L. Chang, et al., "Effect of heat treatment on microstructure and mechanical properties of the hot-isostatic-pressed Inconel 718 powder compact", J. Alloys Compd., 590 (2014),227-232

17. L. Chang, et al;; China Patent Application CN 103551573 A, 2013

18. L. Chang, Ph.D Dissertation, Institute of Metal Research, Chinese Academy of Sciences, Shenyang, China, 2014

19. T. Antonsson, H. Fredriksson, "The effect of cooling rate on the solidification of Inconel 718", Metall. Mater. Trans. B, 36 (2005),85-96

20. Y.C. Fayman, "Microstructural characterization and elemental partitioning in a direct-aged superalloy (DA 718)", Mater. Sci. Eng., 92 (1987),159-171

21. J.R. Li, et al., Adanced high temperature structural material and technology, (Beijing, National defence industry press, 2012), 130

22. E. Arzt, et al., "Practical applications of hotisostatic pressing diagrams: Four case studies", Metall.Trans. A, 14 (1983),211-221

23. W.R. Sun, et al., "Effects of phosphorus on the d-Ni3Nb phase precipitation and the stress rupture properties in alloy 718", Mater. Sci. Eng. A, 247 (1998), 173-179 